\title{
TOURAINE, BURAWOY, GRAMSCI: do social ao político
}

\author{
Leonardo Mello e Silva*
}

\begin{abstract}
O ensaio empreende uma discussão da proposta da sociologia pública de Michael Burawoy, nos anos 2000, a partir da confrontação com a intervenção sociológica de Alain Touraine, formulada nos anos 1970. Pontos de contato são detectados no que diz respeito à relação entre pesquisador e pesquisado, como atores sociais. Problemas e limitações, tanto da intervenção sociológica quanto da sociologia pública, são elencados, trazendo-se como apoio exemplos extraídos de trabalho de campo próprio. O texto vale-se também da inspiração de Antonio Gramsci e sua concepção da relação entre senso comum e intelectuais. Ao invés de um juízo conclusivo, propõe-se um diálogo entre os autores, todos preocupados, à sua maneira, com o destino público ou cívico do conhecimento obtido sobre o mundo social.
\end{abstract}

PALAVRAS-CHAVE: Sociologia pública, intervenção sociológica, senso comum, intelectual orgânico.

A sociologia pública, tal como vem sendo apresentada nos últimos anos, especialmente por Burawoy (2005), dá uma grande importância ao ator social. Este texto explora algumas implicações dessa démarche para a pesquisa ordinária em sociologia, onde o dilema entre agência e estrutura, voluntarismo e determinação, intenção e situação estão recorrentemente presentes. Ao recuperar tal dilema sob a ótica da sociologia pública, a ideia é explorar a dimensão moral da disciplina, assim como alguns paradoxos que ela acaba acarretando.

O principal contraponto à sociologia pública, no que tange às questões que os dilemas elencados acima suscitam, será a sociologia da ação de Alain Touraine. ${ }^{1} \mathrm{O}$ argumento que este artigo tentará desenvolver é o de que existem muitos

* Doutor em Sociologia pela USP. Professor do Departamento de Sociologia da USP.

Av. Prof. Luciano Gualberto, 315 - sala 1063. Cidade Universitária. Cep: 05508-010. São Paulo - SP. leogmsilva@hotmail.com

${ }^{1}$ A referência utilizada para a caracterização da sociologia da ação será principalmente Touraine (1978) e, subsidiariamente, Touraine (1973). Uma apresentação em língua portuguesa pode ser encontrada em Novos Estudos Cebrap, v.1 n. 3, 1982, p. 36-45 ('A Intervenção Sociológica'). Uma utilização da intervenção sociológica no contexto da sociologia brasileira pode ser encontrada em Brant (1990). pontos em comum entre as duas abordagens (sociologia pública e sociologia da ação). Os pontos de divergência, por outro lado, dizem respeito menos à metodologia, e mais à concepção da sociologia diante dos problemas do civismo e da política, de maneira ampla (o que os franceses chamam de le politique, por oposição à la politique).

Com o fito de tentar estabelecer uma ponte entre a discussão sobre as vicissitudes de uma sociologia da ação e suas implicações públicas, por um lado, e o civismo e a política, por outro lado, o texto recorrerá, ainda que de maneira rápida e superficial, a algumas elaborações de Antonio Gramsci. O resultado não tem a menor intenção de ser uma síntese, nem sequer deve ser encarado como a sustentação de uma hipótese forte. Tratase de um exercício pontilhista, fragmentado e tentativo de diálogo entre autores e obras que parecem querer comunicar inquietações próximas, ainda que por vias particulares. Nesse exercício, entram também alguns elementos trazidos de experiência própria de campo, os quais oferecerão um suporte exemplificativo para certos argumentos levantados. 
Vai-se economizar aqui uma apresentação da sociologia pública proposta por Burawoy (2005). Tomase como pressuposto que o leitor tenha alguma familiaridade com ela. As linhas gerais da proposta, bem como os debates que se seguiram, dispõem de acesso público (http://burawoy.berkeley.edu/PS.htm). Muito desse material foi utilizado neste ensaio, e será devidamente indicado quando se fizer recurso a ele.

\section{TOURAINEEA "INTERVENÇÃOSOCIOLÓGICA"}

Touraine define assim o seu 'método de intervenção sociológica': uma 'ação do sociólogo para fazer aparecer as relações sociais e torná-las o objeto principal da análise' (Touraine, 1978, p. 184). Tais relações sociais abrigam sempre relações de poder, fato que fica ocultado pela ordem estabelecida. Por conseguinte, o sociólogo deve fazer apelo àquilo que é dominado ou ao que está 'escondido' pela manutenção do status quo. Em outras palavras, sua atenção deve voltar-se para o protesto e para os que, estando de alguma maneira excluídos, almejam ter a sua voz ouvida. A análise constante de decisões políticas, das relações de autoridade dentro das organizações, enfim, toda a movimentação que remete à criação da sociedade por ela mesma (isto é, por seus atores coletivos) é de relevância e orienta a prática sociológica que procura estar em linha com o caráter dinâmico de seu próprio objeto, ou seja, a própria sociedade. Os movimentos sociais seriam o campo privilegiado para essa abordagem.

Para esse autor, a maneira de desvelar o mecanismo de dominação intrínseco às relações sociais é centrar a análise no que ele chama de luta pelo controle de um campo cultural (Idem, Ibidem) no interior dos movimentos sociais. Para isso, o sociólogo deve desprezar as ideologias em jogo que animam, por sua vez, aquelas lutas. Tais 'ideologias' constituiriam uma armadilha, na medida em que elas também escondem a verdadeira disputa em relação à qual se dá o jogo de poder. 'Ideologias' aqui são entendidas no sentido de uma institucionalização ou uma fixação de certos con- juntos de ideias, sejam eles revolucionários (em direção à mudança) ou conservadores (em direção à manutenção do estado de coisas).

O sociólogo deve ir além das ideologias, mesmo que essas últimas sejam a 'muleta' que as classes em luta utilizam para se reconhecer e legitimar. ${ }^{2}$ Ele, portanto, não considera essas ideologias como vias de acesso, mas meramente como formas de ocultamento da dominação. As ideologias são enganadoras porque são uma racionalização de ideias já cristalizadas, pensadas e institucionalizadas, de grupos em luta pelo poder em um determinado cenário de historicidade. Elas não são, em consequência, capazes de apreender o momento em que as próprias ideias dominantes, ou aquelas solidificadas, cristalizadas em programas políticos ou manifestos, são contestadas ou simplesmente produzidas. O "calor da hora" de um movimento social talvez seja o momento menos apropriado para a captação, por parte do investigador, das razões de fundo dos atores sobre seu engajamento nele. Isso porque eles tendem, nesse caso, a reproduzir as palavras de ordem dos líderes, ao invés de expor as suas próprias razões para o engajamento no conflito.

Touraine menciona, de maneira bastante específica, os métodos mais usuais de pesquisa social, e a razão pela qual os considera insuficientes na análise dos movimentos sociais. A abordagem quantitativa ou estatística, em primeiro lugar, é por definição deslocada e limitada quando se trata de analisar uma situação de contenda e de disputa, como é o caso dos movimentos sociais. $\mathrm{O}$ grande problema com dados obtidos por agregação estatística é que eles se mantêm a uma distância bastante conveniente das lutas e do conflito, com efeitos anódinos sobre eles. Ora, tendo em conta que o conhecimento produzido almeja justamente "servir" para alguns dos atores coletivos em luta, isto é, que possa promover uma intervenção em um mundo social, que é, por definição,

Outros autores, como Gramsci, são muito mais benevolentes em relação ao papel que tais ideologias "espontâneas" desempenham numa perspectiva emancipatória (Gramsci, 1978).

${ }^{3}$ Não em um sentido político (la politique), mas em um sentido, por assim dizer, heurístico. 
mutante - tendo em vista, portanto, esse pressuposto, é de se esperar que os atores vão querer usar aquele conhecimento. A intervenção sociológica seria tanto mais efetiva quanto mais aquela possibilidade estivesse à mão - e não o contrário, o que supõe um conhecimento neutro e um mundo social estático.

Nesse sentido, é conveniente ilustrar com um exemplo de pesquisa próprio ${ }^{4}$ no mundo sindical - onde o conflito entre capital e trabalho anima, ao menos em tese, as investigações sociais, seja de um lado, seja do outro. O dirigente sindical que demanda por estatísticas e dados objetivos acerca de seu setor de atividade, bem como do movimento de emprego dentro dele, está admitindo os 'termos da disputa' em um terreno (o cientificismo 'objetivo') que em tudo se afasta da caracterização de um movimento social dinâmico - ele aceita, subrepticiamente ou não, que o trabalho pode falar "em igualdade de condições" com o capital.

Ao se comportar como movimento socialadmitindo, portanto, o conflito derivado de sua própria condição dependente em relação aos empregadores ou ao "sistema" - o sindicalismo forçosamente se afastaria de uma tal ilusão de "respeitabilidade" e "razoabilidade", encarando as dissimetrias de poder como um problema que lhe diz respeito e que ele tem de enfrentar com as armas típicas dos movimentos sociais: protestos, manifestações, ação organizada, agitação, assembleia, propaganda etc. Esse tópico será retomado adiante.

Outra fonte de alcance limitado para a intervenção sociológica, segundo Touraine, são os documentos históricos. Paradoxalmente, quanto mais bem fornidos pelo movimento social, menos tais documentos provam ser significativos para a compreensão do que está em jogo nos conflitos, uma vez que, muitas vezes, eles tendem a uma versão apologética e a uma autorrepresentação bastante complacente - em uma palavra, uma ideologia. Inversamente, quanto mais rico o conflito, menos

${ }^{4}$ Mas que é certamente partilhado com muitos outros que passaram ou passam pela experiência de assessoria a sindicatos (Bonacich, 2005). registro propagandístico disponível, já que o nível de elaboração ou racionalização das explicações sobre ele é ainda frágil, sem tempo suficiente para assentar-se ideologicamente e virar uma espécie de "monumento". É menos provável, nesses casos, que os atores do movimento estejam todos aptos a prover um discurso unificado - exatamente o contrário do que almejam os líderes políticos. Para o sociólogo interessado em reconstruir o movimento social e as razões que o levaram à cena pública, o pertinente é buscar reconstituir o campo de decisões, onde os ideais que animam a ação estão ainda "em aberto" e pouco institucionalizados (como é o caso de atas, manifestos e teses, com seu lugar-comum de jargão militante).

No entanto, é sobre esses mesmos militantes, como fração privilegiada da população a ser estudada, que deve incidir o investimento do sociólogo, já que eles são os atores por excelência do movimento - pelo menos são aqueles que estão mais envolvidos com ele.

O objetivo da intervenção sociológica é endereçar-se aos militantes dos movimentos sociais e não apenas compreender, mas também aumentar a sua capacidade de ação histórica, isto é, a força e o nível de suas lutas (Touraine, 1978, p. 190).

Os militantes estão ávidos para obter informações sobre o adversário, de que o sociólogo, que estuda justamente o conflito entre grupos, pode dotá-los. O discurso monumental, tal como a lei e as normas, não é capaz de fazer conhecer o próprio movimento e o campo do conflito onde ele está inserido. A intervenção sociológica e o trabalho sobre os atores sinceros do movimento (não os líderes, excessivamente contaminados pela versão edulcorada de sua própria prática) têm o propósito de superar essa limitação, fieis à noção de base de que a sociedade é menos o produto de uma ordem dada (como no funcionalismo) e mais um espaço constante de criação, o que o autor chama de "trabalho da sociedade sobre ela mesma" (Touraine, 1978, p. 186), ou de história cujo roteiro não está conhecido de antemão. Como o próprio militante que, uma vez líder, vira ideólogo, o sociólogo deve evitar a todo o custo a identifica- 
ção, mantendo uma distância que lhe permita exercer o seu papel de "consciência crítica". Trata-se, contudo, de uma posição desconfortável, pois o excesso de zelo no distanciamento pode ser interpretado como desprezo ou altivez diante de seus próprios entrevistados.

Convém observar, ademais, que a intervenção sociológica proposta por Touraine é diferente e específica em relação a outros tipos de intervenção. Tudo depende da maneira como essas modalidades encaram a ordem, o movimento e a ação social, e do peso valorativo atribuído a cada um desses elementos. Enquanto, para uns, a preocupação é captar a resposta de um determinado grupo social a uma ordem qualquer, para Touraine, trata-se de estudar os grupos - reprodução em escala reduzida dos movimentos - postos no interior de um sistema de ação em uma situação de crise, e apontando para condutas de mudança (Touraine, 1978, p. 191). Organizações e instituições costumam se enquadrar na primeira modalidade: a intervenção nessas realidades visa primordialmente a encontrar um modo de relacionamento melhor e uma maior fluidez no seu funcionamento interno. Os grupos, nessa ótica, devem se adaptar às mudanças internas e externas, e a intervenção é vista como uma facilitadora desse processo. Organizações movem-se pelo princípio da autoridade e instituições movem-se pelo princípio da influência. Não é esse o horizonte da proposta de Touraine: ao invés de perseguir condutas adaptativas, o autor se volta para as iniciativas dos grupos para mudar radicalmente a situação. É o campo da historicidade, marcado pelo princípio da dominação, o que lhe interessa.

Haveria ainda outra modalidade de intervenção, associada à busca por acelerar a modernização cultural. As modalidades de intervenção apresentadas na taxonomia tourainiana, enfim, ecoam das divisões do fazer sociológico presentes no esquema de Burawoy, a saber: a sociologia profissional, a sociologia crítica, a sociologia para políticas públicas e a sociologia pública (Burawoy, 2005). Afinal, é facilmente reconhecível a presença da sociologia para políticas públicas nos gru- pos formados a partir de organizações e instituições, ao passo que os movimentos sociais correspondem aos "públicos" (Burawoy, 2007) a que Burawoy se refere na sociologia pública. Touraine se interessa por esses últimos, não pelos primeiros.

Uma precisão histórica, contudo, éfundamental. Quando Touraine elaborou sua proposta de intervenção sociológica junto aos movimentos sociais, esses últimos estavam em ascensão (movimentos estudantis, de protesto, antinucleares, ambientalistas, feministas, etc.) nos países desenvolvidos, tanto quanto em países da periferia (como o Brasil). Era possível, àquela altura, apostar na racionalidade desses movimentos como contratendência ao controle social eà socialização normalizadora oriunda de agências repressivas, formativas ou integradoras (Estado ou Empresa), com sua racionalidade tecnicista e instrumental. O confronto de duas racionalidades distintas pressupunha ainda uma grande margem de deliberação ponderada e de escolha, individual ou coletiva. Tanto é verdade que os dilemas principais do grupo (e do movimento) giravam em torno de questões como: reformismo, voluntarismo, representação. Isso permitia a Touraine descartar de saída os comportamentos simplesmente de recusa, revolta, negação, agressão, evasão ou simples fuga, isto é, comportamentos de exclusão, típicos de uma "massa" ou plebe desorganizada. O que faltava, segundo o autor (Touraine, 1978, p. 191), a esses comportamentos ditos de "saída" (exit), do tipo exclusão versus inclusão, era exatamente o domínio das relações sociais. Essas últimas pressupunham jogos estratégicos, negociação, dilemas políticos típicos (mesmo que objeto de demandas pós-materialistas), ainda que tematizados de forma espontânea pelos atores. Ora, na ausência de relações sociais, a intervenção sociológica não é aplicável. Em outras palavras, a plebe e a massa simplesmente não são tematizáveis. Os movimentos sociais, por seu turno, são manifestações coletivas e organizadas, que se movem no campo da historicidade e da consciência de sua ação, segundo o autor.

Burawoy, por seu turno, escreve em um 
contexto bem diferente, trinta anos depois. Não é o contexto do Welfare State, nem muito menos das "energias utópicas", mas, ao contrário, do neoliberalismo e da fragmentação de "públicos" esgarçados, ao invés de um espaço público ou de uma sociedade civil que aponta para o Estado ou a política. Touraine temia, no exercício da intervenção nos grupos, a aproximação e sobreposição entre grupo e associação, essa última nada mais sendo do que o alter ego do partido político, da seita ou do grupelho radical; ele queria preservar o primeiro contra a segunda, pois a complacência com esses últimos seria o equivalente a dar o braço a torcer para as vanguardas iluminadas (Touraine, 1978, p. 192-3) e, dessa forma, "contaminar" a ação.

Em contexto diverso daquele dos anos 1970, talvez fosse o caso de se reavaliarem determinadas táticas de recusa (no nível individual) como artimanhas críticas que nada têm a ver com um comportamento de massa ou plebe mas, pelo contrário, como afirmação ou "prova de vida". É o que se verá a seguir.

\section{PROBLEMAS DA APLICAÇÃO DA "INTERVEN- ÇÃO SOCIOLÓGICA" NO CONTEXTO ATUAL}

Como se pode perceber, a intervenção sociológica foi concebida para o estudo dos movimentos sociais, e esses também têm uma história e um contexto: a partir do final dos anos 1960, na Europa; a partir do final dos anos 1970, no Brasil. Hoje, o cenário é bem diferente de quando os movimentos sociais emergiram. Particularmente, o declínio valorativo do mundo do trabalho, associado à crise das modalidades coletivas de regulação, vai afetar a forma como o protesto, a recusa e a mudança podem ser tematizados e praticados, nesse âmbito ao menos. Na esfera do sindicalismo e dos conflitos de classe de maneira ampla, é discutível que a carga crítica que ativava, no passado, as reivindicações e as lutas esteja mobilizando potencialmente movimentos sociais, localizados dentro ou fora do local de produção. O medo do desemprego não deixa de ser um fator decisivo, mas é preciso também levar em conta os novos modelos de organização do trabalho, com seus critérios individualizantes e sua ênfase na performance e no arranjo privado. Dito isso, é difícil conceber como movimentos sociais podem emergir desse terreno menos e menos coletivo. Por outro lado, longe está uma pacificação dos conflitos e uma ausência de sofrimento e de experiência de exploração e opressão, produzidas socialmente.

A intervenção sociológica, pensada para atuar junto aos elementos mais salientes dos movimentos sociais, fica, no âmbito do mundo do trabalho e do protesto coletivo, desarmada. Ela é pertinente para as ocasiões de "ascenso" (para usar uma linguagem militante), mas não é tão boa para as ocasiões de "descenso", como se observa na atualidade. Ela teria de levar em conta as formas de (auto) proteção dos trabalhadores contra a mobilização invasiva produzida pelo capital, traduzida nos modelos de gestão do trabalho, ora em operação em firmas e escritórios os mais variados (não é o caso de voltar aqui a uma discussão bem conhecida). A apatia, a recusa ou o comportamento de saída (exit, na acepção hirschamaniana $\mathrm{a}^{5}$ ) podem se tornar formas de recusa e de inconformismo em determinadas situações observadas em locais de trabalho; eles podem ser também, numa palavra, mostradores críticos. Para que sejam identificados, é necessário mais do que apenas ouvir a voz do interlocutor; é preciso levar em conta os silêncios, o comportamento discreto e, para isso, a tentativa de encontrar "bandeiras de luta" pode ser um atalho que não leva a lugar nenhum. O sociólogo ainda investido dos propósitos da intervenção precisaria ir mais fundo e adotar uma postura decididamente empática - desnecessário dizer, parcial - e partilhar do drama social dos atores com os quais está envolvido pelo desejo de produzir algum conhecimento relevante: essa seria a condição para o entendimento completo da situação, que anteriormente era definida, no jargão tourainiano da sociologia da ação, como conflito social. Esse é um dos limites, hoje, da

${ }^{5}$ A referência aqui é Albert Hirschman, Exit, Voice and Loyalty. Edição brasileira, São Paulo: Ed. Perspectiva, 1973. 
aplicação do paradigma da intervenção sociológi$c a$. Mas não significa que as promessas que ela levantou estejam ultrapassadas ou sejam impertinentes. A sociologia pública acaba revolvendo, indiretamente, essas mesmas questões.

\section{A “INTERVENÇÃO SOCIOLÓGICA” EM AÇÃO E SEUS LIMITES}

Lembrando os quatro princípios da intervenção sociológica (Touraine, 1978, p. 186-9), vamos encontrar pistas acerca do como é concebida a interação entre o investigador e o seu objeto de estudo. Isso é o que mais próximo se pode chegar, do ponto de vista daquela abordagem, das respostas às indagações metodológicas que este texto vem suscitando. Para cada um desses princípios será feita uma discussão sobre como eles podem se conectar com uma maneira de fazer pesquisa inspirada na sociologia pública.

Em primeiro lugar, o sociólogo deve entrar em contato e estabelecer uma relação com o movimento social propriamente dito, isto é, participar de uma prática coletiva conflitual com aqueles que estão decidida e conscientemente engajados no movimento. Interpretando tal princípio à luz de uma discussão livre sobre o alcance público da sociologia, pode-se dizer que essa diretiva básica da intervenção sociológica permanece de pé, com a condição, porém, de estender aos comportamentos não-conscientes o direito de constar igualmente como partes do conflito - isso porque os movimentos sociais, na visão tourainiana, dependem justamente de uma consciência de classe de seus participantes.

Como uma técnica de intervenção, prevê-se a constituição de "grupos de análise" com os próprios militantes. Na relação entre sociólogo-investigador versus investigado-objeto, o grupo pode ser simplesmente entendido como a construção de um espaço ético de confiança recíproca (comunitário, se se quiser). Touraine chamava a atenção para o fato de que os grupos de análise tinham uma existência artificial (eram criados pelos sociólogos), porém os seus participantes se viam como representantes de um grupo maior, que os ultrapassava. O mesmo sentimento pode estar presente numa situação de entrevista, na medida em que o entrevistador e o entrevistado se concebem não como indivíduos atomizados, mas como parte de uma comunidade - nacional, linguística, de classe, de origem, ou simplesmente moral. O essencial é a criação de um laço em comum - que pode ser, inclusive e minimamente, o desejo de mudar o estado de coisas. A ideia de um grupo de análise, portanto, não está muito longe da orientação de um compromisso engajado do sociólogo com o seu público.

Em segundo lugar, Touraine chama a atenção para o fato de que não existe incompatibilidade entre o militante e a produção de conhecimento. A existência daquele não é um viés que o conhecimento científico deveria buscar suprimir, uma vez que ele tenderia a "distorcer os fatos"; pelo contrário, no entendimento da sociedade como criação, o militante parece ser mesmo uma condição, se não necessária, ao menos oportuna. O perigo reside não na figura ou no discurso do militante, mas na ideologia que ele secreta. A fim de se evitar essa deformação, o preceito é confrontar o discurso militante com os demais litigantes, assim como com os próprios quadros do movimento a que pertence - tanto os da "base", quanto os líderes. De novo, as possibilidades de extensão dessa abordagem em um novo ambiente e contexto não estão fechadas: é plausível imaginar o mesmo procedimento no quadro de uma conversa (ou entrevista) com uma pessoa ordinária, não-militante, porém parte de um grupo social que se esteja estudando na ocasião (o informante) - vale aqui a mesma observação relativa ao laço em comum, do princípio anterior. Ademais, tratando-se de uma pessoa ordinária como informante, o perigo do efeito de "ideologia" se dissipa. O aspecto "militante", contudo, permanece pertinente, já que o que é importante, nesse caso, não é o grau de participação dela ou dele no movimento, e sim o fato de que ela ou ele tem uma opinião sobre um fato do mundo: é isso o que aproxima o militante escolhi- 
do para um grupo de análise, tal como concebido pela intervenção sociológica, e o informante extraído de uma população determinada. O que se está a sugerir aqui é que o traço em comum entre as duas figuras é a sua não-aleatoriedade. Recorde-se que esse é também o fio que separa o sociólogo público tradicional do sociólogo público orgânico: enquanto o primeiro fala para um público em geral, abstrato, o segundo fala para um público específico, concreto.

Em terceiro lugar, Touraine relembra o papel do investigador como o princípio de inteligibilidade do conflito, tanto para os informantes ${ }^{6}$ privilegiados (os que são escolhidos para o grupo de análise), quanto para os seus interlocutores. A sociologia da ação, como se pode notar, é apropriada para uma situação de conflito. Segundo o autor, a historicidade é um fenômeno de base, presente necessariamente tanto nos "novos movimentos sociais" que tematizam a exclusão, a injustiça e o direito à diferença, quanto nos "velhos movimentos sociais", como o movimento operário e os movimentos reivindicativos urbanos que apontam mais diretamente para a relação com os órgãos estatais. ${ }^{7}$ Tanto num quanto noutro caso, estaríamos diante de algo em comum, e também de um desafio elementar: produzir (e não apenas descrever, analisar ou explicar post festum) o social, a partir da explicitação do campo cultural em que ele transcorre. Lição: o investigador não deve se dissolver no movimento - isso seria render-se à ideologia do grupo. No esquema do autor, o investigador é o repositório do princípio da totalidade (T); esse último, por sua vez, o momento de síntese dos princípios da identidade (I) e da oposição (O) (Touraine, 1978, p. 107-9).

O quarto princípio da intervenção sociológica é que o grupo formado com os militantes de um movimento social ou de uma luta deve reconstruir a sua ação coletiva através da análise que ele mesmo

${ }^{6} \mathrm{O}$ autor não emprega tal termo; essa é uma "tradução“ para aproximar a sua apresentação da "teoria da intervenção" do modo como a terminologia corrente se refere ao repertório da pesquisa de campo.

7 O alto grau de abstração da "historicidade“, definido dessa maneira, não permite captar as distinções históricas das várias situações em que se encontram os movimentos sociais. empreende de suas próprias ações (autoanálise), com o apoio do sociólogo. O mecanismo - que o autor se recusa designar como "técnica" ou como “dinâmica de grupo" (Touraine, 1978, p.189) - em operação é o de uma espécie de simulação compreensiva da ação coletiva empreendida na vida real, a fim de que se possam controlar o seu modo de funcionamento, sua dinâmica e constituição.

O sociólogo somente compreende ou passa a conhecer o movimento social após ter participado da análise da ação (não do movimento propriamente dito) do próprio grupo, o qual ele ajuda, por outro lado, a constituir. Para Touraine, a autoanálise se confunde com a ação militante dos seus membros, em escala reduzida. Mas essa não é a etapa final de conhecimento que o sociólogo produz, pois a autoanálise não é ainda a explicação do fenômeno do movimento social. Ele procede, depois, à interpretação do que observa no "laboratório" ${ }^{\circ}$ do grupo e na análise, mais ou menos como uma etnografia ${ }^{9}$ de sua participação nele. Esse momento de distanciamento é o que garante não apenas certa "isenção" de uma visão muito colada às razões do próprio grupo, mas também - o que é talvez mais importante-conjura o verdadeiro perigo, para o sociólogo, do envolvimento total com o grupo, de forma a se tornar "um deles". Tal perigo-ou tensão entre o envolvimento total e a necessidade de manter certo distanciamento do objetoé tão mais presente quanto mais parcial for o sociólogo; em outras palavras, quanto mais ele tiver assumido como próprias as razões que o movimento social apresenta, supondo que tais razões sejam enfáticas ou radicais, isto é, no dizer de Touraine, "militantes". Uma tensão weberianamente formulada entre as "razões últimas" e uma razão ponderada, o mais possível objetiva. ${ }^{10}$

Vê-se que o elemento empático (embora o autor se refira explicitamente apenas à "simpatia" [Touraine, 1978, p.188], ainda assim de maneira

${ }^{8}$ Esse não é um termo do autor.

9 Também não é um conceito empregado pelo autor.

${ }^{10}$ No mesmo sentido das possibilidades de uma "objetividade" no conhecimento em ciências sociais. Consultar Max Weber em "A ‘objetividade' do conhecimento nas ciências sociais" (1904). 
pouco vigorosa) é muito importante na intervenção sociológica; ele é mesmo uma condição para o conhecimento (análise) do fato - aqui declinado como "movimento" - social. A interpretação, contudo, guarda o componente objetivo, porque é a quebra da empatia, o momento reconstrutivo de contar a história do movimento ou do conflito: enquanto o grupo permanece necessariamente preso às categorias da ação social, o sociólogo opera com as categorias de uma teoria da ação social (Idem, Ibidem).

Não são muito claras as razões pelas quais tais categorias de uma teoria da ação aparecem nesse contexto, ao invés de simplesmente as categorias nativas do grupo. Supõe-se que essa torção acompanhe o dilema básico de todo empreendimento sociológico, quando é chegado o momento de proceder à reconstrução da realidade social; quando a reconstrução é empreendida do ponto de vista de quem é, também, ator. Não importa, para os fins deste ensaio, que a intervenção sociológica tenha feito um enorme esforço metodológico para chegar a um ponto, afinal, tão elementar. O importante é que, com a análise dos movimentos sociais, ela mantém a tensão entre engajamento e exterioridade e, com isso, fornece uma enorme força crítica contra as tentativas de desconsiderar o "envolvimento" como componente legítimo da explicação, de encará-lo como mera nódoa a ser removida na narrativa ou, na melhor das hipóteses, como um simples trampolim para os "dados" mais significativos que o pesquisador pode "arrancar" de seu informante. Touraine afirma que a intervenção do sociólogo é orientada por hipóteses teóricas (o que afasta o perigo de fusão ou integração com o movimento que ele estuda), mas, com isso, ele está se referindo ao seu próprio corpo teórico, no qual o movimento social tem um lugar privilegiado ao lado de outras noções, tais como historicidade, relações de classe, consciência de classe e conflito cultural (não é o momento, contudo, de revirar essas noções, nos limites deste artigo) (Touraine, 1973; 1978).

Ele se refere à dualidade, o que é uma forma neutra de abordar o problema que é, na verdade, essencial: o quanto o conhecimento produzido socialmente (e "interpretado" pelo sociólogo) depende, na verdade, de uma tomada de posição tanto do grupo quanto do pesquisador que se envolve com ele. A dualidade que preserva a não-integração ou fusão, que evita a empatia (ou dissolve a mera "simpatia"), e que protege as funções de analista (do grupo) e intérprete (dos resultados da análise), acaba rebaixando o papel do analista a de um mero "animador" do grupo, limitado à confrontação de posições contrárias, à explicitação do "outro lado" como o máximo de crítica permitido, já que ele deve, a todo o momento, antepor o seu voto de contrição ao envolvimento com o movimento, no caso de perceber um perigo iminente de entendimento compreensivo-que-leva-à-ação ("ser um deles").

Esse problema não existe com o intelectual no sentido gramsciano, por exemplo, uma vez que o "social” (também passível de análise) se resolve na política, isto é, na sociedade civil.

A categoria de "intelectuais" em Gramsci também permite uma aproximação com o sociólogo público. Ela é sugerida (indiretamente) por Burawoy (2005), mas é desenvolvida melhor no tratamento que aquele autor dedica explicitamente ao pensador marxista italiano (Burawoy, 2003). Ali é relembrada a insistência de Gramsci na passagem do "senso comum" da cultura popular, expressão de sua experiência de vida concreta, em "bom senso", passagem essa que é mediada pelos intelectuais. Gramsci preserva a sociedade contra a sua redução à economia e à organização políticopartidária-o que permite legitimamente localizá-lo na linhagem de parentesco das ciências sociais stricto sensu. Mas a arquitetura teórica desse autor é complexa, e o sentido último da importância que reserva à vida social e à estrutura de classes dos países europeus (onde uma revolução passiva substitui a tomada putchista do Estado) é sempre político.

Por isso, a mais importante noção saída dessa reflexão é, sem dúvida, a de sociedade civil, em sua inter-relação com o Estado (Burawoy, 2003, p. 198) - e não a noção corrente de "social”, como é o caso dos filósofos sociais da segunda metade do século dezenove. Para Gramsci, o problema da 
volição ou parcialidade na apreciação do mundo social é um dado constitutivo daquilo que poderíamos chamar de "espaço público" (educação, imprensa, partidos políticos, associações voluntárias etc.). Portanto, qualquer sociologia que ignorasse esse jogo de vontades coletivas seria um constructo artificial. Dessa forma, a sociedade civil demanda intelectuais que explicitem e "forcem a passagem", por assim dizer, das classes para o político - pois é nessa esfera que as mudanças transcorrem. Uma afinidade com a noção de movimento social em Touraine não é, nesse ponto, descabida.

No entanto, há diferenças importantes na apreciação da mecânica do movimento social. Touraine é muito cioso na decantação do militante, por um lado, da organização que ele "representa", por outro lado. Para Gramsci, esse problema não existe, já que o envolvimento político é o ponto de partida.

\section{ALGUNS "PONTOS CEGOS" DA SOCIOLO- GIA PÚBLICA}

Como é bem conhecido, no sentido mundano e usual do termo, ponto cego é aquela superfície do espelho que é incapaz de acusar, numa fração de segundo, para um veículo em movimento, a presença de outro objeto próximo. A impressão é de que se pode proceder à ultrapassagem, mas o ponto cego esconde o perigo. Esta breve seção discorrerá sobre alguns pontos cegos percebidos na apreciação da sociologia pública, tal como apresentada por Burawoy. De novo, o contraponto com a intervenção sociológica de Touraine manterá o tratamento conjunto desses temas, tal como vem sendo feito até aqui.

Talvez se possa dizer que uma das diferenças importantes entre Burawoy e Touraine, no que tange à proposta de intervenção sociológica desse último, é a de que Touraine concebe apenas militantes e pesquisadores no interior do grupo de análise, enquanto Burawoy inclui, além de ativistas e pesquisadores, também os profissionais de serviços sociais (service professionals), mediadores oriundos de ONGs ou funcionários públicos de áreas sociais (Burawoy, 2007, p. 127), todos em colaboração diante de uma demanda levantada por um determinado público.

Tal colaboração consiste em capacitar as classes populares a formular suas reivindicações dentro de uma linguagem dos direitos e da cidadania, além de, no caso dos profissionais em serviços sociais, agir como mediadores diante dos poderes públicos, ao funcionarem como legitimadores e mesmo representantes dos pleitos da comunidade. Mas há um enorme campo a ser trabalhado no interior dessas disputas por competência científica (batalhas em torno da coleta e interpretação dos dados). O problema é que elas não envolvem diretamente o saber dos "de baixo". No entanto, Burawoy permanece advogando uma aliança entre a experiência e os profissionais da pesquisa científica. Não fica muito claro onde entra a sociologia pública aqui; talvez ela seja simplesmente o processador daquele saber profissional no interior da comunidade e de seus porta-vozes.

Perigos análogos aos apontados por Touraine para a intervenção sociológica são acusados também por Burawoy (Ibidem). São eles: o vanguardismo, por um lado, e, por outro lado, a imersão completa no grupo, quando os pesquisadores são capturados pela comunidade. Essas duas notações, muito parecidas no diagnóstico dos problemas envolvidos no campo de uma sociologia da ação, fazem crer que são uma atualização de velhos dilemas que sempre vêm à tona quando se trata de escapar do normativismo de uma postura pretensamente objetiva e exterior, nas ciências sociais. Burawoy "resolve" esses dilemas propondo uma "mutualidade balanceada" na relação entre comunidade e pesquisadores, baseada na reciprocidade. ${ }^{11}$

Porém um tópico sensível nessa relação de reciprocidade é quando ele postula, com a maior das boas intenções, uma produção conjunta de poder. Supõe-se, nesse caso, que há uma relação

${ }^{11}$ Burawoy também se refere a uma "accountability mútua“ (Burawoy, 2007, p. 133). 
simétrica entre o capital cultural e social (e - por que não? - capital científico) do lado dos pesquisadores, e o patrimônio de mobilização e conhecimento concreto da situação, por parte da comunidade. Uma troca justa? Ou, colocando de outro modo: produzem ambos os blocos um poder equivalente? A resposta parece negativa. A descrição feita no início sobre os problemas envolvidos na relação do assessor sindical e seu público ou cliente sugere já por onde passa o ponto cego. As razões para isso devem-se ao fato de que o "capital científico" retira seu poder de legitimação sob a forma de um mistério que o grupo subalterno não penetra e não domina, por não deter as regras do seu manejo, ao mesmo tempo em que presta uma aceitação reverente a ele.

Curiosamente, é o próprio Burawoy quem chamou a atenção, indiretamente, para esse cerco sociológico à filosofia espontânea popular (seu "senso comum", segundo Gramsci), numa nota em que compara a concepção desse autor sobre as possibilidades de esclarecimento das classes subalternas, que seriam ilimitadas em sua (dela) sede de saber e ilustração, confrontando-as com os constrangimentos necessários para uma boa ordem baseada na solidariedade orgânica de Durkheim (Burawoy, 2003): enquanto os operários de Turim do período conselhista (1919-1920) ${ }^{12}$ buscavam quebrar as barreiras da divisão do trabalho manual e intelectual, a sociologia debutante advogava a contrição em nome da estabilidade e do perigo da anomia. Exemplos da experiência do trabalho de campo podem, nesse caso, oferecer um suporte mais empírico aos problemas envolvidos.

O primeiro exemplo vem de uma incursão junto a trabalhadores de fábricas de confecção sob programas de qualidade total e células de produção. O maior inimigo à aproximação do pesquisador com os informantes, em uma base deliberadamente dialógica e conversacional, foi exatamente a reserva que eles demonstraram em relação a uma postura, da parte do pesquisador, tão pouco convencional para um "cientista" ou investigador "da

${ }^{12}$ Para uma história social do período conselhista de Gramsci, consultar Dias (1987). universidade", a qual deveria, segundo eles, ser mais rigorosa e menos "frouxa". Em outros termos, deveria seguir alguns procedimentos que eles não são capazes de explicitar, mas que funcionam imaginariamente como garantidores de respeitabilidade do empreendimento científico: questionários, perguntas precisas e fechadas, ausência de dúvida, emprego de gráficos e tabelas para sustentar os argumentos etc. É certo que uma das causas para tal comportamento reservado, por parte dos informantes, poderia ser a própria não-convivência com eles, bem como a falta de qualquer trabalho prévio de aproximação com o ambiente do campo, assim como a ausência de um processo mais duradouro e sistemático de "ganhar a sua confiança".

Essa observação é plausível e metodologicamente acertada. Mas é pouco provável que uma imersão mais estendida no tempo fosse capaz de dissolver aquelas resistências em um sentido mais perene e menos circunstancial, porque as forças que contribuem para confirmar aquela percepção reificada de ciência vêm de muitas outras fontes da sociedade, e não apenas uma vaga noção preconceituosa veiculada pelos meios de comunicação. A começar pela própria fábrica onde eles trabalham, com a panóplia de relatórios e pesquisas para fins de certificação que eles têm de preencher, além de, em menor medida, a própria formação escolar. Portanto, trata-se de forças que, em seu conjunto, confirmam, aos olhos dos informantes, o acerto do juízo deles, não o do pesquisador. De novo, sempre se poderá arguir, contra certo fatalismo do investigador, de que seria preciso, nesse caso, insistir, estreitar mais, enfim, os laços de comunicação com o objeto, perseverar no campo e agir contra uma tendência relapsa de pautar-se pelas impressões mais óbvias etc. Mas o problema do timing é um problema real quando não se é "um deles" - afinal, é preciso escrever um relatório da investigação e descrever um mundo para os "iguais" (os pares).

O segundo exemplo vem de uma situação de negociação coletiva no meio sindical, e o caso em pauta é a demanda por expertise dos assessores do lado trabalhista. Um relacionamento dura- 
douro entre a assessoria militante e a direção não foi suficiente para definir o critério a ser adotado na escolha do discurso empregado no embate com os patrões na mesa de negociações. O discurso eficaz foi aquele baseado na especialização profissional, prioritariamente do economista ou do advogado, e não o discurso político ou sociológico-afinal, eram daquelas duas fontes que vinha o empowerment do movimento sindical diante dos empresários e também do Estado, na ótica dos próprios sindicalistas, em suma, sua fonte de legitimidade. ${ }^{13}$ Mais do que isso: de respeitabilidade social.

No limite, a demanda sindical por conhecimento técnico especializado conduziu até a terceirização das atividades de assessoria: escritórios de advocacia mais focados nos processos usuais dos associados e encomendas de pesquisas econômicas just-in-case. Aqui, mais uma contraprova da permanência da força persuasiva do argumento técnico e científico no interior das classes populares. Os sociólogos públicos orgânicos, bem como os investigadores ligados aos movimentos sociais e movidos pela intervenção sociológica, devem lutar contra "inimigos internos poderosos": no fundo, são as mesmas forças simbólicas (e que depois desembocam em recursos materiais, tais como oferta de empregos, contratação de consultorias e investimento em cursos de capacitação) que transformam o grupo em "clientela”, e evitam uma aproximação comunicativa.

Esse último problema atinge também a intervenção sociológica de Touraine, na medida em que a concepção metodológica aberta, que ela esposa com a sociologia pública de Burawoy, pode ser capturada instrumentalmente pelo grupo de análise. Desse modo, o conhecimento partilhado e obtido de maneira comunicativa se converte em arma de legitimação do próprio grupo diante de outros com os quais se está disputando espaço e poder. O universo sindical é ainda um bom posto de observação, e o assessor parece ser a figura privilegiada na confluência dos vetores opostos de

\footnotetext{
${ }^{13}$ Uma experiência similar e muito interessante, também em diálogo com a sociologia pública, está relatada em Bonacich (2005).
}

doação e usurpação. A doação diz respeito a "pôrse à disposição de uma causa" junto aos sindicalistas ou a qualquer movimento social - o que inclui não apenas a criação e disponibilização de uma massa de dados mas principalmente uma interpretação discursivamente elaborada sobre a situação em tela ${ }^{14}$, enquanto que a usurpação diz respeito a tomar o produto reflexivo da intervenção sociológica desvirtuando-o para uma finalidade prática.

Embora seja difícil o controle preciso desses deslocamentos, o assessor - ele mesmo se autorrepresentando como um ativista - costuma perceber quando o resultado de seu trabalho é apropriado de maneira mais corporativa do que estava tacitamente "acertado" entre pesquisador e os atores de um determinado movimento social com o qual ele se envolve e com relação ao qual ele imagina estar "servindo", ao invés de simplesmente realizando uma "prestação de serviço", ou ainda, o que é pior, servindo a uma luta interna de poder.

\section{A INOCÊNCIA PERDIDA DA SOCIOLOGIA PÚBLICA}

Na verdade, existe uma fricção não muito bem assentada em Burawoy entre o papel privilegiado que ele atribui à sociologia pública orgânica e os quatro outros tipos de sociologia de seu esquema: sociologia profissional, sociologia para políticas públicas (policy sociology), sociologia crítica e sociologia pública tradicional. Em alguns momentos de sua argumentação, a sociologia pública orgânica parece claramente superior, no sentido de possuir o acesso a um conhecimento dos "de baixo" que pode ser também transformador da realidade (de dominação) em que eles se encontram inseridos. Em outros momentos, contudo, a defesa dos tipos de sociologia, em sua diferença específica, esconde tal consideração valorativa em nome de uma boa convivência com cada qual, ainda que observados os limites inerentes a cada um deles: a

\footnotetext{
${ }^{14}$ Esse talvez seja o ativo mais precioso do labor sociológi-
} co, nessas situaçóes. 
sociologia profissional, alheia às implicações pré e pós-pesquisa, a sociologia para políticas públicas, pautada pela agenda das agências de fomento (públicas ou privadas), e a sociologia crítica confinada à academia e aos pares.

Um dos momentos em que isso fica explícito é quando ele confronta a sociologia pública orgânica com a sociologia pública tradicional (o alvo aqui é Bourdieu), na busca dessa última de preservar a autonomia e a universalidade dos intelectuais - o corporativismo do universal seria, afinal, idealista e "desumano"15 (Burawoy, 2005a, p.430). Em outro momento, como de resto nas diversas ocasiões ao longo de reações à recepção de seu projeto, Burawoy se esforça em clamar pelo auxílio dos outros tipos de sociologia, como passos incompletos (mas necessários) da empreitada mais acabada, que, segundo seu ponto de vista, seria apanágio da sociologia pública orgânica. Tal estratégia conciliatória termina por redimi-lo das dificuldades de convivência entre esses quatro tipos, bem como de uma crítica interna de cada um deles, assim como das incompatibilidades e exclusões que a escolha de cada um implica. Eles são vistos como componentes mais ou menos neutros de um jogo de que se adiciona ou subtrai os principais elementos definidores do perfil de cada um dos componentes, sem prejuízo para o todo. ${ }^{16}$

${ }^{15}$ No sentido, como diria Gramsci, de um conhecimento “desencarnado". A lembrança aqui é, de novo, devida a Dias (1987).

${ }^{16}$ Procurei apontar para essas incompatibilidades num registro muito próximo ao deste texto, em comunicação apresentada no XIII Congresso Brasileiro de Sociologia, maio de 2007, Recife: "Prática de pesquisa e Sociologia Pública: uma discussão em torno de cruzamentos possíveis e outros nem tanto”. Posteriormente publicada na revista Sociologias, v .11, 2009, p. 76-99. com uma visão moral do mundo em que as escolhas privadas feitas pelos cidadãos não devem afetar os juízos concernentes ao bem público - nesse caso em discussão, a ciência seria o correspondente do "bem público"-, pois que isso colocaria em risco o direito dos outros aos mesmos bens.

É plausível supor que, em países de modernização acelerada como o Brasil, tais problemas de consolidação científica e de legitimidade institucional empurrem celeremente para um comportamento de feitio instrumental, muito próximo do perfil oferecido pela sociologia profissional ou para políticas públicas, no âmbito das ciências sociais (não é preciso olhar muito longe para perceber que esse é um processo iniciado há muito tempo, apenas reforçado pela globalização neoliberal). Inversamente, em meios intelectuais e científicos que oferecem alguma resistência cultural à modernização social de todas as esferas de vida, é esperável um anteparo crítico ao nivelamento dos quatro tipos ideais de sociologia desenhados por Burawoy. Eles não seriam, desse ponto de vista, intercambiáveis, variando meramente segundo seus respectivos "públicos".

Um quadro comparativo das sociologias nacionais deveria indicar, se a especulação conduzida até aqui estiver correta, um gradiente onde as sociologias mais afetadas pela solicitação profissionalizante, cientificista e produtivista seriam aquelas onde o empuxe da modernização obrigou a uma espécie de desistência do "embate de deuses" ou sobre os "fins últimos", no sentido weberiano, aceitando como inelutável a via única da burocratização e do funcionalismo. Enquanto os países superdesenvolvidos do Norte se viram às voltas com movimentos sociais que questionaram, no interior de suas próprias sociedades, o modo de vida e os valores hegemônicos do materialismo aquisitivo, os países do Sul (na melhor das hipóteses) viviam "milagres econômicos" que alavancavam suas economias para um padrão também "desenvolvido", o que inclui, por derivação, padrões de reconhecimento pelo mercado acadêmico e universitário que estivessem en phase com os do Norte. Isso conduz a um derradeiro ponto levantado por Burawoy, que é o da diferença entre o intelectual orgânico e o sociólogo orgânico. 
O sociólogo público, diz Burawoy, "sabe do que está falando” (apud Swedberg, 2007, p. 321), enquanto o intelectual público, conquanto bem intencionado, não sabe; isto é, ele não é um especialista. Essa parece ser a imagem mais acabada da representação de uma espécie de ciência (social) em nome da transformação social. O sociólogo público assume a especialização e divisão funcional (moderna) dos interesses e das competências e investe resolutamente em uma delas. A diferença é que não se deixa capturar pela ilusão da "pura ciência”, e assume os valores e a carga normativa da escolha de seu estudo.

Ora, se, de fato, a inspiração para a figura do sociólogo público orgânico vem da figura do intelectual orgânico gramsciano, então devemos ser consequentes no seu emprego. Não se pode perder de vista que a noção de intelectual orgânico em Gramsci não está apenas relacionada com o partido, o “Príncipe moderno”. Está também relacionada com as mudanças na base produtiva da sociedade, na passagem do capitalismo concorrencial para o capitalismo organizado, monopolista e fordista. Nesse sentido, o intelectual orgânico não é apenas o agitador ou o publicista cuja arena são os círculos literário-jornalísticos; é, então, o técnico, o engenheiro, o administrador e o profissional de recursos humanos, de acordo com a nova organização do trabalho. Essa imagem do novo intelectual orgânico está de acordo com o "novo operário" que ele anteviu em seu ensaio sobre o americanismo. É também, parece, a imagem que povoa a definição do sociólogo público orgânico. $\mathrm{O}$ intelectual -mesmo o orgânico-, no novo mundo, fica deslocado se não estiver bem escorado em algo sobre o qual ele possa falar com conhecimento de causa; se não estiver inserido na divisão do trabalho geral da sociedade; se não estiver participando de um "trabalho produtivo". Caso contrário, ficará confinado às hostes de uma (velha) pequena burguesia desconectada do conflito moderno.

Já quanto ao papel do sociólogo público tradicional, este não fica muito claro. Por vezes, ele surge como um divulgador amplo dos resultados de sua pesquisa para um público inespecífico e indiferenciado, para isso utilizando todas as mídias a que tem acesso: jornais, rádio, televisão, revistas de ampla circulação, palestras em associações civis, debates em fóruns públicos com presença de pessoas comuns etc. Nesse caso, ele apenas populariza os resultados de uma pesquisa feita dentro dos cânones da sociologia profissional (Burawoy, 2005b, p.13). Por vezes, contudo, o sociólogo público tradicional é aquele que, mesmo tendo participado ativamente e junto a um movimento social, circunscreve seu uso "científico" ao espaço acadêmico, defendendo a autonomia dele, como se fez referência acima a Pierre Bourdieu. ${ }^{17}$

\section{DO SOCIAL AO POLÍTICO: à guisa de conclusão}

Como se pode perceber, há muitas perguntas no ar quando se trata de operacionalizar a sociologia pública, em sua diferença específica com os outros tipos de sociologia. O debate que ela tem suscitado no ambiente acadêmico de língua inglesa é alvissareiro e pode ser atestado pela frequência de intervenções em revistas e coletâneas, as quais, muitas vezes, reproduzem debates e confrontações entre sociólogos.

Mas, além de perguntas, a sociologia levanta também antigos dilemas - participação e objetividade, ação e análise, ator e estrutura etc. - da própria disciplina. Isso é próprio de seu caráter reflexivo. Aceitar a reflexividade é já tomar uma posição entre as quatro sociologias de Burawoy. Outros empreendimentos anteriores ao dele passaram muito próximos desses mesmos dilemas. É o que se procurou mostrar quando se mobilizou o aparato da intervenção sociológica de Alain Touraine, hoje quase esquecida com o correspondente arrefecimento dos movimentos sociais que lhe forneceram inspiração. O cenário da globalização talvez esteja a exigir uma nova onda de reflexividade da sociologia e, quem sabe, de ação, para o que a proposta de Burawoy pode fornecer uma excelen-

${ }^{17}$ É dessa forma que um autor como Richard Sweedberg entende o escopo de uma sociologia pública (Swedberg, 2005, p. 320). 
te ferramenta para aqueles que dessa tarefa queiram se acercar. Mas os vetores vindos na direção contrária são ainda bastante fortes, conforme se sugeriu acima, com a hipótese da modernização acelerada que impele a uma standardização do pensamento social. Touraine, a seu modo, reagiu à dominância do funcionalismo na sociologia, tentando criar uma alternativa teórica e metodológica (aqui se viu apenas uma parte muito limitada dela) que devolvesse a historicidade aos processos sociais. Ele sustentava que as sociedades humanas tinham a capacidade de agir sobre elas mesmas, o que significava a possibilidade de mudar ou superar o seu modo de funcionamento; a aprendizagem desse processo passava pela política:

As normas que comandam as relações sociais não são intangíveis; elas são em grande parte o resultado de decisões e, por conseguinte, podem ser modificadas como resultado de uma mudança nas relações de força ou de influência entre os atores, assim como das modificações sobrevindas no ambiente (Touraine, 1973, p. 25).

Não está em condições este pequeno ensaio de proceder a uma avaliação de seu projeto. Mas foi possível identificar ali uma estratégia de pesquisa que contém surpreendentemente muitos pontos semelhantes com a sociologia pública, enquanto pontos de divergência foram também esboçados - como no caso do esforço da intervenção sociológica em evitar a identificação do pesquisador com o grupo (o que ela designa como "dualidade"). Não está claro, contudo, o quão radical é a distância da sociologia pública orgânica com respeito a essa interdição que a abordagem tourainiana havia colocado para si mesma relativamente à dualidade. Isso vai depender, é o que parece, da relação da sociologia pública orgânica com os outros tipos específicos de sociologia desenhados por Burawoy.

Permanece, porém, a incômoda sensação de que a chave para furar o círculo dos dilemas com os quais a sociologia se defronta, e que voltam aqui e ali, esteja em outro lugar. Foi por isso que se fez uma remissão a Gramsci, juntamente com seu entendimento do que seja "sociedade civil". Para Burawoy, a sociedade civil é formada de "públi- cos"; ela é plural (e contraditória). Talvez não esteja muito longe da verdade afirmar que, para Touraine, tais "públicos" são os movimentos sociais teorizados por ele. Ambos os autores guardam uma reticência em relação à noção de uma sociedade de massas, pois essa última é indiferenciada e impenetrável. Para Gramsci, a sociedade civil não distingue o social do político. As tomadas de posição, no âmbito da cidadania e do civismo, envolvem tomadas de posição de partes da sociedade contra outras partes. O sociólogo não é convidado a observar essa luta; ele participa dela.

O problema parece residir na clarificação do que consiste exatamente a "sociedade civil". Burawoy é muito claro quando afirma que a sociedade civil é uma reação à tirania do mercado no capitalismo (Burawoy, 2005b); uma forma de proteção da sociedade, na linha de Polanyi. Touraine e os autores que vieram depois dele (porém antes da consolidação do que Burawoy chama de "terceira onda de mercadorização") pontuaram a sociedade civil como uma esfera de proteção principalmente contra o Estado, tomando como referência de época os países do socialismo real e os países saídos de regimes autoritário-ditatoriais (como o Brasil). ${ }^{18}$

Esses deslocamentos da sociedade civil certamente têm a ver com as mudanças históricas no entretempo. Em Gramsci, a sociedade civil era bifronte, atuando tanto no mercado quanto no Estado. Esse ponto de vista pode ter a vantagem de captar mais realisticamente as novas reacomodações tectônicas das camadas (ou partes) da sociedade civil, uma vez que as associações e organizações comunitárias da sociedade não são mais uma proteção segura contra o mercado, nem o Estado é um bloco blindado, avesso às pressões intermitentes dos movimentos.

(Recebido para publicação em abril de 2009) (Aceito em julho de 2009)

\footnotetext{
${ }^{18}$ Talvez a mais influente obra nessa direção tenha sido o verdadeiro ‘tratado' sobre sociedade civil produzido por Cohen e Arato (1992).
} 


\section{REFERÊNCIAS}

BONACICH, Edna. Working with the labor movement: a personal journey in organic public sociology. The American Sociologist. Fall/Winter. p. 105-120, 2005.

BRANT, Vinicius C. (coord.) Paulínia: petróleo e política. Campinas e São Paulo: Sindicato dos Petroleiros de Campinas e Paulínia/CEBRAP, 1990.

BURAWOY, Michael. For a sociological marxism: the complementary convergence of Antonio Gramsci and Kar Polanyi'. Politics \& Society. v. 31, n. 2, p. 193-261, 2003.

For public sociology. American Sociological

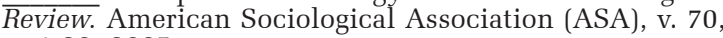
p. 4-28, 2005

Response: public sociology: populist fad or path to renewal? The British Journal of Sociology. University of London, v. 56 n. 3 p. 417-432, 2005a.

The third wave sociology and the end of pure science. The American Sociologist. American Sociological Association (ASA), n. 36, p.151-165, 2005b.
Private troubles and public issues. In: BARLOW, Andrew, Collaborations for social justice. Lanham: Rowman and Littlefield, 2007.

COHEN, J.L.; ARATO, A. Civil society and political theory. Cambridge: MIT Press, 1992.

DIAS, Edmundo. F. Democracia operária. Campinas: Ed. da Unicamp, Coleção Teses (2 vols.), 1987.

GRAMSCI, Antonio. Os Intelectuais e a organização da cultura. Rio de Janeiro: Civilização Brasileira, 1978.

SWEDBERG, Richard. Public Sociology and Economic Sociology: Introductory remarks. Socio-Economic Review, V. 5, n. 2, p. 319-326, 2007.

TOURAINE, Alain. Le voix et le regard. Sociologie des mouvements sociaux. Paris: Seuil, Follio Essais, 1978

Production de la société. Paris: Seuil, Collections Sociologie, 1973. 


\section{TOURAINE, BURAWOY, GRAMSCI: from social to politics}

\section{Leonardo Mello e Silva}

This essay discusses the idea of a Public Sociology proposed by Michael Burawoy in the 2000 s confronting it with the Sociology Intervention approached by Alain Touraine in the 1970s. Points of contact are detected regarding the relationship between the researcher and the researched, as social actors. Problems and shortcomings from either Public Sociology and Sociology Intervention are otherwise pointed out, which is emphasized by taking to the forefront pieces from own fieldwork. The paper appeals also to Antonio Gramsci's notion of the common sense and the role of intellectuals. Instead of a definite statement, a dialogue among the authors is proposed, as all of them are concerned about the public outcome from the knowledge coming from the social world.

KEY wORDS: public sociology, sociology intervention, common sense, organic intellectual

\section{TOURAINE, BURAWOY, GRAMSCI: du social au politique}

\section{Leonardo Mello e Silva}

Ce travail entame une discussion au sujet de la proposition de sociologie publique de Michael Burawoy, dans les années 2000, en la confrontant à l'intervention sociologique d'Alain Touraine formulée dans les années 1970. On y détecte des points de rencontres quant à la relation entre chercheurs et sujets de recherche considérés comme acteurs sociaux. Des problèmes et des restrictions, à la fois au niveau de l'intervention sociologique que de la sociologie publique, sont répertoriés en s'appuyant sur des exemples provenant de recherches sur le terrain. Le texte s'inspire aussi de Antonio Gramsci et de sa conception sur la relation entre le sens commun et les intellectuels. Plutôt que d'en arriver à une conclusion, on propose un dialogue entre les auteurs, tous préoccupés à leur manière par le destin public ou civique de la connaissance acquise sur le monde social.

Mots-CLÉS: sociologie publique, intervention sociologique, sens commun, intellectuel organique.

Leonardo Mello e Silva - Doutor em Sociologia pela USP. Professor do Departamento de Sociologia da USP. Foi Diretor do Centro de Estudos dos Direitos da Cidadania (Cenedic - USP). Desenvolve pesquisas nas áreas de Sociologia do Trabalho. Sua mais recente publicação é o livro intitulado Trabalho em grupo, sociabilidade privada. 